\title{
MATING, OVULATION AND CORPUS LUTEUM FUNCTION IN THE VOLE, MICROTUS AGRESTIS
}

\author{
S. R. MILLIGAN \\ Department of Agricultural Science, University of Oxford, \\ Parks Road, Oxford OX1 3PF
}

(Received 5th March 1974)

\begin{abstract}
Summary. A study of the relationship between the mating behaviour of the vole and the induction of ovulation and CL function is described. A single intromission or an injection of LH-RF constitute stimuli which induce ovulation, but normally give rise to $\mathrm{CL}$ that degenerate soon after formation. More prolonged mating, or mechanical stimulation of the vagina and cervix given after a separate ovulatory stimulus, result in the maintenance of the CL. Mechanical genital stimulation is effective in inducing CL maintenance when given up to $48 \mathrm{hr}$ after an LHRF injection. Similarities, therefore, are apparent between the vole, an induced ovulator, and spontaneous ovulators such as the rat, mouse and hamster.
\end{abstract}

\section{INTRODUCTION}

The functional relationship between mating and aspects of reproduction other than the mere transference of semen is particularly obvious in those species which are normally dependent on coitus to stimulate either ovulation (e.g. rabbit, cat and ferret) or CL function (e.g. rat, mouse and hamster). The relationship has been investigated in a number of species (see review by Dewsbury, 1972) and these studies have indicated that the actual temporal pattern of copulation of a species may be of considerable significance to successful reproduction. The present study was undertaken to analyse the relationship between the mating behaviour of Microtus agrestis and the initiation of neuroendocrine mechanisms necessary for pregnancy. These voles seemed particularly suitable for such an analysis since they ovulate reflexly (Austin, 1957; Breed, 1967) and ovulation and CL maintenance can be dissociated (Milligan, 1974a).

\section{MATERIALS AND METHODS}

Laboratory bred $M$. agrestis were used in all experiments and were maintained as described by Breed (1969). Females were normally 2- to 3-month-old virgins judged to be mature by the appearance of vaginal smears consisting of predominantly cornified cells on 3 consecutive days (Milligan, 1974a). Females were caged singly for at least 2 days before treatment. Daily vaginal smears 
were classified as described by Milligan (1974a). Males were fertile adults from the breeding colony.

For mating trials, the male was placed in a clean cage 5 min before introduction of the female. If mating had not begun within 5 min of pairing, the female was returned to her cage for a further week before being introduced to a new male. Females which failed to mate during three such trials were discarded. In Exps 1 and 2, involving 163 virgin females, mating began within 5 min of pairing in 135 out of 228 trials.

During copulation by the vole, $M$. agrestis (Milligan, 1974b), intromission (median duration $18 \mathrm{sec}$ ) is accompanied by pelvic thrusting. A series of one or more intromissions precedes ejaculation and each such series is referred to as an 'ejaculatory series'. A number of ejaculatory series occurs during a period of mating under laboratory conditions. The occurrence of ejaculation was confirmed by the male's behaviour and by the presence of a copulatory plug or spermatozoa in the vagina.

\section{Experiment 1}

Males were permitted to mount eleven females (five virgin and six parous) that had adhesive plaster over the vaginal aperture to prevent intromission. The pairs were separated 3 min after the first mount.

Forty-two other mating pairs were separated after one of the following: $5 \mathrm{sec}$ from the start of the first intromission (i.e. incomplete intromission); $10 \mathrm{sec}$ from the start of the first intromission (i.e. incomplete intromission); the first intromission, provided that this did not end in ejaculation; the first ejaculatory series (of one or more intromissions); the second ejaculatory series; the fourth ejaculatory series. All females were returned to their original cages after the separation and were later killed (see below).

\section{Experiment 2}

A regimen of mechanical stimulation was designed in an attempt to mimic the multiple intromission/multiple ejaculation mating pattern, and was modelled on the median values of behavioural measures obtained from observations of copulating laboratory voles (Milligan, 1974b). To simulate an intromission, a glass rod was moved within the vagina for a period of $20 \mathrm{sec}$. An ejaculatory series was simulated by giving three such periods of stimulation separated by approximately 8-sec pauses. Four of the simulated ejaculatory series were given, with an interval of $5 \frac{1}{2} \mathrm{~min}$ between each complete series. The instrument used was either a glass rod $(2.5 \mathrm{~mm}$ in diam.), moved manually to and fro in the vagina, or a similar rod attached to the drive spindle of a $1.5-\mathrm{V}$ electric toothbrush (Boots Ltd) run off a 3.0 V supply. The motor-driven rod ('vibrator') rotated rapidly through $45^{\circ}$ at more than $30 \mathrm{~Hz}$.

Mechanical stimulation of the vagina and cervix was applied to eleven virgin females. Other females were each given a separate ovulatory stimulus by pairing with a male and separating the pair immediately following the completion of the first intromission (see Exp. 1). Those with males that ejaculated were discarded, but the others were immediately given one of three treatments: genital stimulation using the hand-operated rod, genital stimulation with the vibrator, 
or handling as in the previous two treatments but without any genital stimulation.

\section{Experiment 3}

Seventy-two females were anaesthetized with ether and a saline solution of LH-RF (the synthetic decapeptide) was injected into the external jugular vein. The dose of LH-RF varied between 25 and $100 \mathrm{ng}$. At various times afterwards (15 min, $6 \mathrm{hr}, 24 \mathrm{hr}$ or $48 \mathrm{hr}$ ), comparable females were either stimulated with the vibrator ('stimulated'), or given a similar amount of handling but with no genital stimulation ('handled'). Additional 'stimulated' females were used to test the ability of the CL to support a decidual reaction (see below). Five other females were injected with saline and stimulated 15 min later.

\section{Functional activity of $C L$}

The ability of the CL to support a decidual reaction was tested in some females. Using ether anaesthesia, the left uterine horn was subjected to trauma $3 \frac{1}{2}$ days after mating (Exp. 2) or injection of LH-RF (Exp. 3). The horn was scratched three or four times along the anti-mesometrial surface with a burred needle inserted at the oviducal end through small incisions in the skin, body wall and uterus. These females were killed 3 days later.

\section{Autopsy}

The reproductive state of each female was assessed by examining the vaginal smears during, and the ovarian structure at the end of, treatment. Following ovulation, the cornified smears typical of virgin females (Austin, 1957; Breed, 1967; Milligan, 1974a) were usually interrupted by a period of thin or leucocytic smears. Females that showed such an interruption were normally killed when cornified smears returned; those that continued to show cornified smears after treatment were killed within 4 days.

Fresh ovaries were examined for luteinized structures: these can be easily and reliably identified as pink or white opaque bodies which contrast with the stroma and translucent follicles. Paraffin wax-embedded sections of ovaries possessing luteinized bodies, and of uteri subjected to trauma, were prepared and stained with Ehrlich's haematoxylin and eosin. The diameters of luteinized structures, except those containing ova, were measured.

\section{RESULTS}

Three reproductive states were recognized in females following ovulation induced by coitus or injection of LH-RF: females (a) showed only a transient interruption of the cornified vaginal smears and possessed degenerating $\mathrm{CL}$ ('short-lived' CL) when killed 3 or 4 days after coitus or injection, (b) became pseudopregnant, possessing either histologically healthy CL when killed 3 or 4 days after coitus or injection, or degenerating CL on the return of cornified smears after 9 to 10 days, or (c) became pregnant, showing thin or leucocytic smears until parturition. 
Effect of various amounts of copulation

The results of Exp. 1 (Table 1) indicate that the response of females to mating (with respect to ovulation and the development of the CL) is dependent on the amount of mating experienced. Repeated mounts without intromission were not sufficient to induce ovulation in the five virgin females, but three of the six parous females ovulated and became pseudopregnant. Only a small proportion of females ovulated when they experienced less than one complete intromission, but the majority ovulated when they experienced one or more complete intromissions.

Table 1. Induction of ovulation and luteal function in voles after different amounts of mating

\begin{tabular}{|c|c|c|c|c|}
\hline \multirow[b]{2}{*}{ Treatment* } & \multicolumn{4}{|c|}{ No. of females } \\
\hline & Total & Ovulating & $\begin{array}{c}\text { With } \\
\text { short-lived } \\
C L\end{array}$ & $\begin{array}{c}\text { Pregnant or } \\
\text { pseudopregnant }\end{array}$ \\
\hline $\begin{array}{l}\text { Mounting only } \\
\text { Parous } \\
\text { Virgin } \\
\text { Intromission for } 5 \mathrm{sec} \\
\text { Intromission for } 10 \mathrm{sec} \\
\text { One complete intromission } \\
\text { (mean duration } \pm \text { S.E. }=22 \pm 3.5 \mathrm{sec} \text { ) } \\
\text { One ejaculatory series } \\
\text { Two ejaculatory series } \\
\text { Four ejaculatory series }\end{array}$ & $\begin{array}{r}6 \\
5 \\
4 \\
4 \\
\\
12 \\
6 \\
6 \\
10\end{array}$ & $\begin{array}{r}3 \\
0 \\
1 \\
1 \\
11 \\
6 \\
6 \\
10\end{array}$ & $\begin{array}{l}0 \\
0 \\
1 \\
8 \\
3 \\
2 \\
0\end{array}$ & $\begin{array}{r}3 \\
1 \\
0 \\
3 \\
3 \\
4 \\
10\end{array}$ \\
\hline
\end{tabular}

* See text for further explanation.

The CL resulting from ovulation were either 'functional', i.e. characteristic of pregnancy or pseudopregnancy, or short-lived. The proportion of ovulating females that developed functional GL after experiencing one or more complete intromissions increased with the amount of mating experienced.

\section{Effect of mechanical stimulation}

The eleven virgin females subjected to mechanical stimulation only did not ovulate.

There were no significant differences between the other three treatments of Exp. 2 (Table 2) in either the proportion of females ovulating $\left(\chi^{2}=3.64\right.$; $P>0 \cdot 1)$, or in the number of CL/ovulating female $\left(\chi^{2}=1.82 ; P>0 \cdot 1\right)$. The duration of the intromissions (the ovulatory stimuli) was not significantly different between the treatments. Most of the females which were only handled following the intromission developed short-lived CL and only a few became pseudopregnant. A significantly higher proportion of females became pseudopregnant when the limited mating stimulus was followed by genital stimulation using either the hand-operated rod $\left(\chi^{2}=6.44 ; P<0.01\right)$ or the vibrator $\left(\chi^{2}=17.65 ; P<0.001\right)$. Although a higher proportion of ovulating females became pseudopregnant after stimulation with the vibrator than with the handoperated glass rod, this difference was not significant $\left(\chi^{2}=2.81 ; P>0.05\right)$. 


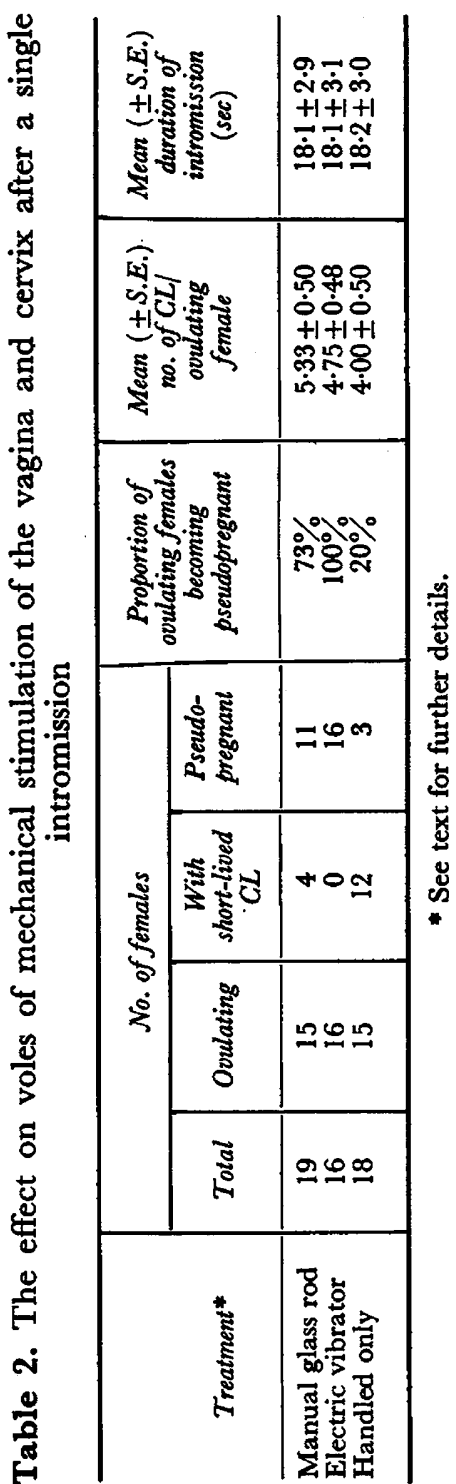


Females possessing functional CL as a result of mechanical stimulation following an intromission showed a marked decidual response to uterine trauma.

\section{Effect of LH-RF and mechanical stimulation}

None of the five females in Exp. 3 that were treated with saline and given artificial stimulation ovulated. There was no significant difference in either the proportion of females ovulating $\left(\chi^{2}=2.56 ; P>0.1\right)$ or the number of CL/ ovulating female $(t=1.46 ; P>0.1)$ between the 'stimulated' and 'handled' voles treated with LH-RF (Table 3). All 'handled' females that ovulated developed short-lived CL, but one female killed 4 days after injection possessed a single histologically healthy CL in addition to four other degenerating ones. By contrast, many of the females given genital stimulation between $15 \mathrm{~min}$ and $48 \mathrm{hr}$ after LH-RF injection became pseudopregnant. In the females given this treatment (the 'stimulated' females of Table 3 and the additional females used to test the functional activity of the $\mathrm{CL}$ ), stimulation at $15 \mathrm{~min}, 6 \mathrm{hr}, 24 \mathrm{hr}$ and $48 \mathrm{hr}$ after the LH-RF injection was effective in maintaining the CL in 7/10

Table 3. The effect on voles of mechanical stimulation or handling after LH-RF injection

\begin{tabular}{l|c|c|c|c}
\hline \multirow{2}{*}{ Treatment } & \multicolumn{4}{|c}{ No. of females } \\
\cline { 2 - 5 } & Total & Ovulating & $\begin{array}{c}\text { With short-lived } \\
C L\end{array}$ & $\begin{array}{c}\text { Pseudopregnant or with } \\
\text { histologically healthy CL }\end{array}$ \\
\hline Stimulated & 38 & 30 & 11 & 19 \\
Handled & 34 & 21 & $21^{*}$ & $1^{*}$ \\
\hline
\end{tabular}

* One female with both types of GL (see text).

$(70 \%), 8 / 10(80 \%), 8 / 15(53 \%)$ and $6 / 18(33 \%)$ of the ovulating females, respectively. Females which developed histologically healthy $\mathrm{CL}$ after stimulation at 6 or $24 \mathrm{hr}$ showed a marked decidual reaction in response to uterine trauma. Of the females in which the CL were maintained following stimulation at $48 \mathrm{hr}$, only one had a characteristic pseudopregnancy. The others had histologically healthy CL but little change in the cornified smear pattern occurred before they were killed at 4 days (three females) or $6 \frac{1}{2}$ days (two females) after the LH-RF injection. The uteri of the latter two females were subjected to trauma, but no decidual reaction was evoked.

\section{DISCUSSION}

Microtus agrestis, in common with other microtine rodents (Richmond \& Conaway, 1969; Clarke, Clulow \& Greig, 1970; Clulow \& Mallory, 1970; Kirkpatrick \& Valentine, 1970; Hasler \& Banks, 1973), is an induced or reflex ovulator (Austin, 1957; Breed, 1967; Breed \& Clarke, 1970a). Irrespective of the ovulatory stimulus, induced ovulators such as the rabbit, cat and ferret normally develop functional $\mathrm{CL}$ and become pseudopregnant or pregnant following ovulation (Everett, 1961; Conaway, 1971). M. agrestis differs from these 'typical' induced ovulators in that, in some circumstances, ovulation may 
give rise to GL that begin to degenerate (Table 4) within about 2 days of the inducing stimulus (i.e. within about $1 \frac{1}{2}$ days of ovulation, as ovulation occurs 9 to $12 \mathrm{hr}$ after an inducing stimulus: Austin, 1957; Breed \& Clarke, 1970a). Short-lived CL may occur after ovulations induced by 'remote' male stimuli (Milligan, 1974a), limited amounts of mating (Exps 1 and 2) and injections of LH-RF (Exp. 3) or LH (Milligan, 1974b). The life-span of these CL is in marked contrast to that of the CL associated with pregnancy or pseudopregnancy (Breed \& Clarke, 1970b; see also Table 4, first line) and they are unable to support a decidual reaction (Milligan, 1974b).

Table 4. The diameter of CL in female voles killed at various times after an ovulation-inducing stimulus

\begin{tabular}{|c|c|c|c|c|c|}
\hline Nature of inducing stimulus & 1 & & Days after inducing stimulus & $\begin{array}{r}\text { simulus } \\
4\end{array}$ & 5 \\
\hline $\begin{array}{l}\text { Unrestricted mating* } \\
\text { (2 days with male) }\end{array}$ & $599 \pm 24 \cdot 1$ & $744 \underset{(3)}{ \pm} 5 \cdot 8$ & $\underset{(4)}{749 \pm 25 \cdot 9}$ & $820 \pm \frac{27 \cdot 3}{(4)}$ & $\underset{(4)}{740 \pm 35 \cdot 9}$ \\
\hline $\begin{array}{l}\text { Close contact with male; } \\
\text { no copulationt }\end{array}$ & & $726 \frac{ \pm}{(3)} 49 \cdot 9$ & $436 \pm 57$ & $265 \underset{(3)}{ \pm} 20 \cdot 7$ & $175 \pm \frac{18 \cdot 5}{(3)}$ \\
\hline Single intromission only $\ddagger$ & & $709 \frac{ \pm}{(3)} 5 \cdot 3$ & $\frac{309 \pm 66 \cdot 4}{(2)}$ & $229 \frac{ \pm}{(2)} 6.4$ & \\
\hline LH-RF intravenously (100 $\mathrm{ng})^{*}$ & & $\frac{605 \pm 61 \cdot 5}{(2)}$ & $300 \underset{(2)}{ \pm} 6 \cdot 9$ & $169 \frac{ \pm}{(2)} 1.9$ & \\
\hline LH-RF subcutaneously (200 ng)* & & $666 \pm 10 \cdot 1$ & & $214 \underset{(2)}{ \pm} 9 \cdot 4$ & $127 \underset{(2)}{ \pm} 0.9$ \\
\hline LH subcutaneously $(20 \mu \mathrm{g})^{*}$ & & $\frac{668 \pm 65 \cdot 8}{(2)}$ & & $\frac{280 \pm 31 \cdot 0}{(2)}$ & $158 \frac{ \pm}{(2)} 4 \cdot 5$ \\
\hline
\end{tabular}

Luteal diameters $( \pm$ S.E.) are in $\mu \mathrm{m}$. Figures in parentheses represent the number of females.

* Data from Milligan (1974b).

† Data from Milligan (1974a); time from inducing stimulus an approximation.

$\$$ Data from Experiment 2 and additional females.

Although the existence of these short-lived CL indicates that ovulation may occur independently of the development of CL function, stimulation of both processes must occur if mating is to result in successful pregnancy. Limited amounts of mating (e.g. a single intromission) readily induce ovulation but only short-lived CL are usually formed, and more prolonged mating is normally necessary to induce the development of functional CL (Exp. 1). The vole's multiple intromission/multiple ejaculation mating pattern meets the stimulus requirements for both processes. The results from the virgin and parous females that had been mounted only (Exp. 1) suggest that there may be a difference in the response to copulatory stimuli of females of different reproductive status.

Mechanical stimulation of the vagina and cervix can mimic mating by inducing ovulation in some other reflex ovulators (cat-Greulich, 1934; minkEnders, 1952; rabbit-Carlyle \& Williams, 1961), but previous attempts to induce ovulation by this technique in $M$. californicus (Greenwald, 1956), $M$. agrestis and Clethrionomys glareolus (Clarke \& Clulow, 1973) have been unsuccessful. The failure of mechanical genital stimulation to induce ovulation in the present study (Exps 2 and 3 ) is in contrast to the response even to limited mating (Exp. 1). This suggests that the mechanical stimulation may have failed 
to mimic some essential feature of the penile stimulation (e.g. penile spines) and/or that other stimuli associated with the male may be important. The fact that mounting alone (Exp. 1) or the presence of males nearby (Milligan, 1974a) are both able to induce ovulation suggests that other stimuli may be involved.

Genital stimulation was able to mimic, however, that part of the mating process that causes the development of functional CL. A single intromission or an injection of LH-RF normally gave rise only to short-lived CL, but if either of these ovulatory stimuli was followed by mechanical stimulation, a high proportion of females developed functional CL (Exps 2 and 3). Simple artificial mechanical stimulation also may induce pseudopregnancy in the rat, mouse, hamster and Mongolian gerbil (De Feo, 1966; Diamond \& Yanagimachi, 1968; Diamond, 1970; Wu, 1974). In the mouse, the ejaculatory reflex is the effective copulatory stimulus (McGill \& Coughlin, 1970; McGill, 1972), and in the hamster, mating provides a more effective stimulus than mechanical stimulation (Diamond \& Yanagimachi, 1968). To what extent the regimen of stimulation used in the present study provided the same effective stimuli as copulation is uncertain, but ejaculation was neither necessary, nor necessarily sufficient, to induce the maintenance of the CL (Exp. 1). Cornified epithelial spines, similar to those described in rats (Beach \& Levinson, 1950), occur on the glans penis of microtine rodents (Hooper \& Hart, 1962), including the male voles of our laboratory colony (Milligan, 1974b). These spines may be involved in the induction of neuroendocrine mechanisms leading to ovulation and luteal maintenance (Zarrow \& Clark, 1968).

The present results indicate that ovulation and the development of CL function in $M$. agrestis are dependent on reflex mechanisms that appear to have different stimulus requirements for their activation. Ovulation is readily induced by very limited mating but not by artificial genital stimulation, but the development of functional CL is induced either by more prolonged mating or by artificial stimulation. Although the effective stimuli for the induction of both processes are normally provided within a fairly limited period by a single unrestricted session of mating, the results of Exp. 3 indicated that the mechanical stimulation could still induce functional CL in some voles even when given many hours after an ovulatory stimulus. The maintenance of the CL resulting from artificial stimulation $48 \mathrm{hr}$ after LH-RF administration did not, however, appear to be accompanied by the development of full secretory function.

It is apparent that there are similarities between the vole, an induced ovulator, and spontaneously ovulating animals such as the rat, mouse and hamster. In these latter animals, mating also stimulates the development of functional CL (Everett, 1961), and the CL of the rat and the hamster, like those of the vole, retain the capacity for the development of full secretory function for some time after ovulation (Nikitovitch-Winer \& Everett, 1958; Greenwald, 1963; Staples, 1965). In addition, the distinction between the nature of ovulation in the vole and these other animals is not absolute, as induced ovulations can also occur in rats (e.g. Zarrow \& Clark, 1968; Aron, Roos \& Asch, 1970; BrownGrant, Davidson \& Greig, 1973) and possibly in mice (Allen, 1922; Togari, 1927). 


\section{ACKNOWLEDGMENTS}

I am especially grateful to $\mathrm{Dr}$ J. R. Clarke for his invaluable encouragement and supervision of this work; to Professor J. H. Burnett for providing facilities; to Dr H. M. Charlton for providing the electric toothbrush, and to Miss Judith Tompkins for maintaining the animal colony. Part of the equipment used for the work was provided through a grant to J.R.C. from The Royal Society.

This work was carried out during the tenure of a post-graduate studentship from the Science Research Council.

\section{REFERENCES}

Allen, E. (1922) The oestrous cycle in the mouse. Am. F. Anat. 30, 297-371.

Aron, C., Roos, J. \& Asch, G. (1970) Effect of removal of the olfactory bulbs on mating behaviour and ovulation in the rat. Neuroendocrinology, 6, 109-117.

Austin, G. R. (1957) Oestrus and ovulation in the field vole (Microtus agrestis). F. Endocr. 15, iv.

BEACH, F. A. \& Levinson, G. (1950) Effects of androgen on the gians penis and mating behaviour of castrated male rats. F. exp. Zool. 114, 159-171.

BREED, W. G. (1967) Ovulation in the genus Microtus. Nature, Lond. 214, 826.

BREED, W. G. (1969) Oestrus and ovarian histology in the lactating vole (Microtus agrestis). F. Reprod. Fert. 18, 33-42.

Breed, W. G. \& Clarke, J. R. (1970a) Ovulation and associated histological changes in the ovary following coitus in the vole (Microtus agrestis). F. Reprod. Fert. 22, 173-175.

BREED, W. G. \& ClaRKE, J. R. (1970b) Ovarian changes during pregnancy and pseudo-pregnancy in the vole, Microtus agrestis. F. Reprod. Fert. 23, 447-456.

Brown-Grant, K., Davidson, J. M. \& Greig, F. (1973) Induced ovulation in albino rats exposed to constant light. F. Endocr. 57, 7-22.

Garlyle, A. \& Williams, T. D. (1961) Artificially induced ovulation in the rabbit. F. Physiol., Lond. $157,42 P$.

Clarke, J. R. \& Glulow, F. V. (1973) The effect of successive matings upon bank vole (Clethrionomys glareolus) and vole (Microtus agrestis) ovaries. In The Development and Maturation of the Ovary and its Functions, pp. 160-1 70. Ed. H. Peters. International Congress Series No. 267, Excerpta Medica, Amsterdam.

Glarke, J. R., Glulow, F. V. \& Greig, F. (1970) Ovulation in the bank vole, Clethrionomys glareolus. F. Reprod. Fert. 23, 531.

Clulow, F. V. \& Mallory, F. F. (1970) Oestrus and induced ovulation in the meadow vole, Microtus pennsylvanicus. F. Reprod. Fert. 23, 341-343.

Conaway, C. H. (1971) Ecological adaptation and mammalian reproduction. Biol. Reprod. 4, 239-247.

DE FEo, V. J. (1966) Vaginal-cervical vibrator: a simple and effective method for the induction of pseudopregnancy in the rat. Endocrinology, 79, 440-444.

DewsBury, D. A. (1972) Patterns of copulatory behaviour in male mammals. Q. Rev. Biol. 47, 1-33.

Diamond, M. (1970) Intromission pattern and species vaginal code in relation to induction of pseudopregnancy. Science, N.Y. 169, 995-997.

Diamond, M. \& Yanagimachi, R. (1968) Induction of pseudopregnancy in the golden hamster. $\mathcal{F}$. Reprod. Fert. 17, 165-168.

Enders, R. K. (1952) Reproduction in the mink (Mustela vison). Proc. Am. phil. Soc. 96, 691-775.

EVERETt, J. W. (1961) The mammalian female reproductive cycle and its controlling mechanisms. In Sex and Internal Secretions, 3rd edn, Vol. 1, pp. 497-555. Ed. W. G. Young. Williams \& Wilkins, Baltimore.

GreEnwald, G. S. (1956) The reproductive cycle of the field mouse (Microtus californicus). F. Mammal. $37,213-222$.

Greenwald, G. S. (1963) Coital block to superovulation in the hamster. F. Reprod. Fert. 5, 217-223.

GREUlich, W. W. (1934) Artificially induced ovulation in the cat (Felis domestica). Anat. Rec. 58, 217-224.

HASLER, J. F. \& BANKs, E. M. (1973) Ovulation and ovum maturation in the collared lemming (Dicrostonyx groenlandicus). Biol. Reprod. $9,88$.

Hooper, E. T. \& Hart, B. S. (1962) A synopsis of recent North American microtine rodents. Misc. Publs Mus. Zool. Univ. Mich. 120.

KirkPatrick, R. L. \& VALENTine, G. L. (1970) Reproduction in captive pine voles, Microtus pinetorum. F. Mammal. 51, 779-795. 
McGill, T. E. (1972) Pre-ejaculatory stimulation does not induce luteal activity in the mouse, Mus musculus. Horm. \& Behav. 3, 83-85.

McGild, T. E. \& Coughlin, R. G. (1970) Ejaculatory reflex and luteal activity induction in $M u s$ musculus. J. Reprod. Fert. 21, 215-220.

Miluigan, S. R. (1974a) Social environment and ovulation in the vole, Microtus agrestis. J. Reprod. Fert. 41, 35-47.

Milligan, S. R. (1974b) Some aspects of reproduction in the female vole, Microtus agrestis. D.Phil. thesis, University of Oxford.

Nikitovitch-Winer, M. \& EveretT, J. W. (1958) Comparative study of luteotrophin secretion by hypophysial autotransplants in the rat. Effects of site and stages of the estrous cycle. Endocrinology, $62,522-532$.

Richmond, M. \& Conaway, C. H. (1969) Induced ovulation and oestrus in Microtus oclirogaster. $\mathcal{J}$. Reprod. Fert., Suppl. 6, 357-376.

Staples, R. E. (1965) Induction of pseudopregnancy in the rat by vaginal stimulation at various stages of the oestrous cycle. Anat. Rec. 152, 499-502.

Tocari, G. H. (1927) On the ovulation of the mouse. Nagoya F. med. Sci. 2, 17-50.

Wu, J. T. (1974) Artificial insemination and induction of pregnancy in the Mongolian gerbil (Meriones unguiculatus). 7. Reprod. Fert. 37, 139-140.

ZarRow, M. X. \& CLARK, J. H. (1968) Ovulation following vaginal stimulation in a spontaneous ovulator and its implications. 7. Endocr. 40, 343-352. 